\title{
ANALISIS PROSEDUR PENERJEMAHAN BUKU MOTIVASI KARYA STEPHEN R. COVEY
}

\author{
Roswani Siregar \\ Universitas Al-Azhar Medan, Indonesia
}

\begin{abstract}
Abstrak
Penerjemahan telah mengambil peran penting dalam komunikasi global dan sebagai sumber pengetahuan diantara masyarakat dengan budaya dan bahasa yang berbeda. Penelitian ini berkaitan dengan analisis terhadap prosedur penerjemahan Jenis penelitian ini adalah deskriptif-kualitatif yang berfokus pada analisis produk terjemahan. Sampel dari penelitian ini adalah 430 pasang data teks (Inggris dan Indonesia). Dari analisis terhadap isi ditemukan sembilan prosedur penerjemahan yang digunakan dengan jumlahmasing-masing:literal (181), calque (5), peminjaman (32), penambahan (105), penghilangan (33), modulasi (27), transposisi (24), ekivalensi (21), dan adaptasi (2). Ketiga teknik yang pertama (literal, pinjaman dan calque) yang berorientasi pada bahasa sumber sedangkan sisanya berorientasi pada bahasa sasaran. Temuan ini mengungkapkan proporsi terjemahan harfiah dan terjemahan komunikatif masing-masing 50,70\% dan 49,30\%.
\end{abstract}

Kata Kunci: Penerjemahan, Prosedur, Analisis, Korpus

\begin{abstract}
Translation plays a crucial role in global communication and diffusion of knowledge among the communities with different cultures and languages.This study deals with the investigation of translation procedures.The type of study is descriptive-qualitative that focuses on translation product analysis. The sample of the study is 430 data pairs of both text (English and Indonesian). The content analysis revealed nine translation procedures, they areliteral (181), calque (5), borrowing (32), addition (105), omission (33), modulation (27), Transposition (24), Equivalence (21), and Adaptation (2). The first three of techniques (literal, borrowing and calque) are oriented to source text while the rest (addition, omission, modulation, transposition, equivalence, and adaptation) are oriented to target text.Procedures that oriented to source text is referred todirect translation, while those to target text is referred tooblique translation.The finding revealed the proportion of literal translation and communicative translation are $50.70 \%$ and $49.30 \%$ respectively.
\end{abstract}

Keywords: translation, procedures, direct, analysis, corpus

\section{PENDAHULUAN}

1.1 Latar Belakang Masalah

Bahasa merupakan alat interaksi sosial dan menjadi elemen penting dalam kehidupanbermasyarakat. Namun, di antara ribuan bahasa di dunia, tidak ada dua bahasa yang benarbenarsama. Oleh karena itu, karya-karya terjemahan berperan pentingsebagai sumber pengetahuan diantara masyarakat dengan budaya dan bahasa yang berbeda.

Jutaan buku-buku asing telah diterjemahkan ke dalam bahasa Indonesia. Pada 2015 saja, ada sekitar 1.400 penerbitdi Indonesia yang menerbitkan rata-rata 24.000 judul buku asing per tahun (Abrams,2015). Terjemahan sangat penting dalam pengembangan bahasa nasional dan memainkan peran penting dalam 
transfer pengetahuan dan pembangunan bangsa (Murtisari, 2015).

Kenyataannya di dunia ini, tidak ada dua bahasa yang persis sama. Larson menyebutkan bahwa setiap bahasa memiliki bentuk tersendiri untuk mengungkapkan suatu makna. Oleh karena itu, makna dari suatu bahasa dapat direpresentasikan dalam bentuk yang sangat berbeda pada bahasa lain. Maka kesenjangan bahasa menjadi masalah dalam penerjemahan. (Larson dalam Siregar R., 2016:22)

Masalah kesepadananmerupakan masalah utama dari teori dan praktek penerjemahan karena proses penerjemahan selalu melibatkan pencarian padanan. Menurut Baker (1992: 21), kesulitan yang timbul dalam menemukan padanan disebabkan oleh 2 hal yakni konsep khusus budaya dan kata bahasa sumber yang tidak tersedia dalam bahasa sasaran, sehingga diperlukan prosedur tertentu dalam suatu hasil terjemahan.

\subsection{Tujuan}

Sehubungan dengan hal tersebut di atas, penelitian ini bertujuan untuk menganalisis prosedur penerjemahan yang digunakan dalam proses penerjemahan buku asing ke dalam bahasa Indonesia. Korpus dalam penelitian ini adalah Chapter 5 dari karya Stephen R. Covey yang berjudul "Express Your Voice" sebagai teks sumber (Tsu) beserta terjemahannya dalam bahasa Indonesia. Karya-karya Covey telah mempengaruhi jutaan pembaca di seluruh dunia, termasuk Indonesia, inilah alasan peneliti tertarik untuk melakukan analisis prosedur penerjemahan buku tersebut.

\section{METODE}

Penelitian ini menggunakan pendekatan deskriptif kualitatif dengan teknik analisis ini. Metode ini kerap digunakan dalam penelitian linguistik terapan. Pendekatan deskriptif kualitatif mencakup penggambaran secara kualitatif fakta, data atau objek material yang bukan berupa rangkaian angka, melainkan berupa ungkapan bahasa atau wacana apapun itu bentuknya melalui interpretasi yang tepat dan sistematis.Wibowo (2011: 43). Pengumpulan data yang terdiri dari kata, frase, klausa dan kalimat dilakukan dengan teknik purposive sampling.Sejalan dengan tujuan penelitian ini, dilakukan analisis isi (content analysis) terhadap korpus untuk mengidentifikasi berbagai karakteristik khusus dari sampel secara objektif dan sistematis.

\section{HASIL DAN PEMBAHASAN}

Prosedur penerjemahan dipahami sebagai instrumen analisis tekstual yang dalam kombinasi dengan instrumen lainnya memungkinkan kita untuk mempelajari bagaimana produk terjemahan yang dihasilkan. Penelitian ini menggunakan teknik analisis tunggal. Dengan mengamati data, ada 9 prosedur penerjemahan yang digunakan dalam proses penerjemahan Chapter 5 dari karya Stephen R. Covey yang berjudul "Express Your Voice". Korpus dalam peneterdiri dari 430 pasangan data dalam satuan kata, frase, klausa dan kalimat.

Table 3.1 Frekuensi Prosedur Penerjemahan

\begin{tabular}{clcc}
\hline No. & \multicolumn{1}{c}{ Teknik } & F & \% \\
\hline 1 & borrowing & 32 & 7.44 \\
2 & calque & 5 & 1.16 \\
3 & literal & 181 & 42.09 \\
4 & transposition & 24 & 5.58 \\
5 & modulation & 27 & 6.28 \\
6 & equivalence & 21 & 4.88 \\
7 & adaptation & 2 & 0.47 \\
8 & addition & 105 & 24.42 \\
9 & omission/deletion & 33 & 7.67 \\
\hline & Total & $\mathbf{4 3 0}$ & $\mathbf{1 0 0}$ \\
\hline
\end{tabular}




\subsection{Peminjaman (Borrowing)}

Terdapat 32 pasangan data yang mengandung teknik peminjaman. Diantaranya:

Visionis seeing with the mind's eye what is possible in people, in projects, in causes and in enterprises.

Visiberarti dengan mata batin melihat kemungkinan yang terdapat di dalam diri orang, dalam proyek, dalam hal-hal yang pantas diperjuangkan, dan dalam usaha kita.

This is true synergy, where the whole is greater than the sum of the parts.

Ini merupakan sinergi yang sesungguhnya, di mana keseluruhannya lebih besar daripada jumlah total dari bagian-bagiannya.

\subsection{Calque}

Ditemukan5 pasangan data yang menggunakan calque. Diantaranya:

The visionary leader thinks big, thinks new, thinks ahead - and most important, is in touch with the deep structure of human consciousness and creative potentials.

Pemimpin visioner berpikir besar, berpikir secara baru, berpikir ke depan, dan yang lebih penting lagi, bersentuhan dengan struktur yang mendalam dari kesadaran dan potensi kreatif manusia.

He built one of the most disciplined militaryindustrial machines that the world has ever seen.

Dia membangun salah satu mesin industrimiliter yang paling disiplin yang pernah disaksikan oleh dunia.

\subsection{Harfiah (Literal)}

Dari 430 pasangan data, ditemukan 181 penerjemahan harfiah.

1) Penerjemahan harfiah dalam bentuk kata

\section{commitment}

social mirror

attribute

expansion

community

foundation

harmony

organization komitmen

cermin sosial

atribut

ekspansi

komunitas

fondasi

harmoni

organisasi
2) Penerjemahan harfiah dalam bentuk frase

$\begin{array}{ll}\text { formal position } & \text { posisi formal } \\ \text { international } & \text { komunitas } \\ \text { community } & \text { internasional } \\ \text { economic recession } & \text { resesi ekonomi } \\ \text { military-industrial } & \text { mesin industri- } \\ \text { machine } & \text { militer } \\ \text { emotional intelligence } & \text { kecerdasan } \\ & \text { emosional } \\ \text { positive energy } & \text { energi positif } \\ \text { religious tradition } & \text { tradisi agama } \\ \text { professional career } & \text { karir profesional }\end{array}$

3) Penerjemahan harfiah dalam bentuk klausa dan kalimat

When people have no vision, when they neglect the development of the mind's capacity to create, they fall prey to the human tendency toward victimism (see the lower road of Figure 5.1).

Bila orang tak punya visi, bila mereka mengabaikan perkembangan kemampuan pikiran untuk mencipta, mereka akan jatuh pada kecenderungan manusiawi ke arah victimism (viktimisme, merasa menjadi korban) (lihat jalur bawah pada Gambar 5.1).

When conscience governs vision, discipline and passion, leadership endures and changes the world for good.

Bila nurani mengarahkan visi, disiplin, dan gairah, kepemimpinan akan terus bertahan dan mengubah dunia ke arah yang baik.

\subsection{Transposisi (Transposition)}

Ditemukan 24 pasangan data yang dikategorikan mengalami transposisi. Dua diantaranya:

Lack of conscience was his downfall.

Kehancurannya disebabkan oleh tiadanya nurani.

You might be interested to know that a longtime colleague of mine visited Stone in Uganda several years after this film was made.

Sekembali dari kunjungannya kepada Stone di Uganda, salah seorang teman saya mengungkapkan kesannya, 


\subsection{Modulasi (Modulation)}

Terdapat 27 pasangan data yang diidentifikasi menggunakan teknik modulasi. Diantaranya

Does it give me a sense of "calling," a cause worthy of my commitment?

Apakah dengan visi itu saya merasa punya "panggilan" tertentu, suatu alasan atau tujuan yang pantas mendapat komitmen dari diri saya?

In fact, enthusiasm becomes a moral imperative, making the person part of the solution rather than part of the problem of feeling essentially hopeless and helpless.

$\underline{\text { Bagi orang seperti itu, antusiasme menjadi }}$ tuntutan moral, yang membuat dia menjadi bagian dari pemecahan masalah, dan bukan menjadi bagian dari masalah dengan merasa tak berdaya dan putus asa.

\subsection{Ekivalensi (Equivalence)}

Berdasarkan hasil analisis, ada 21 pasangan data yang dikelompokkan sebagai ekivalensi. Diantaranya:

Gandhi's vision, discipline and passion were driven by conscience, and he became a servant to the cause and the people.

Visi, disiplin, dan gairah hidup Gandhi, didorong oleh nuraninya, dan dia menjadi pelayan rakyat dalam mengejar tujuan mulianya.

People are illogical, unreasonable, and selfcentered. Love them anyway.

Orang sering keterlaluan, tidak logis, dan hanya mementingkan diri; bagaimanapun, maafkanlah mereka.

\subsection{Adaptasi (Adaptation)}

Terdapat 2 pasangan data yang menggunakan adaptasi

The biggest men and women with the biggest ideas can be shot down by the smallest men and women with the smallest minds. Think big anyway.

Bila engkau mendapat ketenangan dan kebahagiaan, mungkin saja orang lain jadi iri; bagaimanapun, berbabagialah.

People really need help but may attack you if you do help them. Help people anyway.
Engkau lihat, akhirnya ini adalah urusan antara engkau dan Tuhanmu; bagaimanapun ini bukan urusan antara engkau dan mereka.

\subsection{Penambahan (Addition)}

Terdapat 105pasangan data yang menggunakan teknik penambahan. Dua diantaranya adalah:

Each of us has immeasurable power and capacity to reinvent our lives.

Masing-masing dari kita memiliki kekuatan dan kemampuan tak terkira untuk menemukan kembali dan menata ulang hidup kita.

\section{Conscience sees life on a continuum.}

Nurani memandang kehidupan ini sebagai kontinum, suatu rentang perkara yang tidak bisa dibagi dengan begitu mudahnya seperti pembagian hitam-putih.

\subsection{Penghilangan (Omission)}

Hasil analisis menunjukkan 33 pasangan data yang mengalami penghilangan (ommision). Diantaranya sebagai berikut:

Conscience is the inward moral sense of what is right and what is wrong, the drive toward meaning and contribution.

Nurani adalah kesadaran moral kita mengenai apa yang baik dan buruk, dan dorongan untuk menggapai makna dan memberi sumbangan nyata.

I completed graduate school and began teaching at a historically black college in Little Rock, Arkansas.

Setelah lulus S2, saya mulai mengajar di sebuah kampus, khusus untuk warga kulit hitam, di Little Rock, Arkansas.

Disamping penghilangan sebagian teks sumber, terdapat penghilangan seluruh bagian pasangan data atau penghapusan. Pasangan data yang terdiri dari teks sumber tidak memiliki pasangan dalam teks sasaran.

People favor underdogs but follow only top dogs. Fight for a few underdogs anyway.

Give the world the best you have and 
you'll get kicked in the teeth.

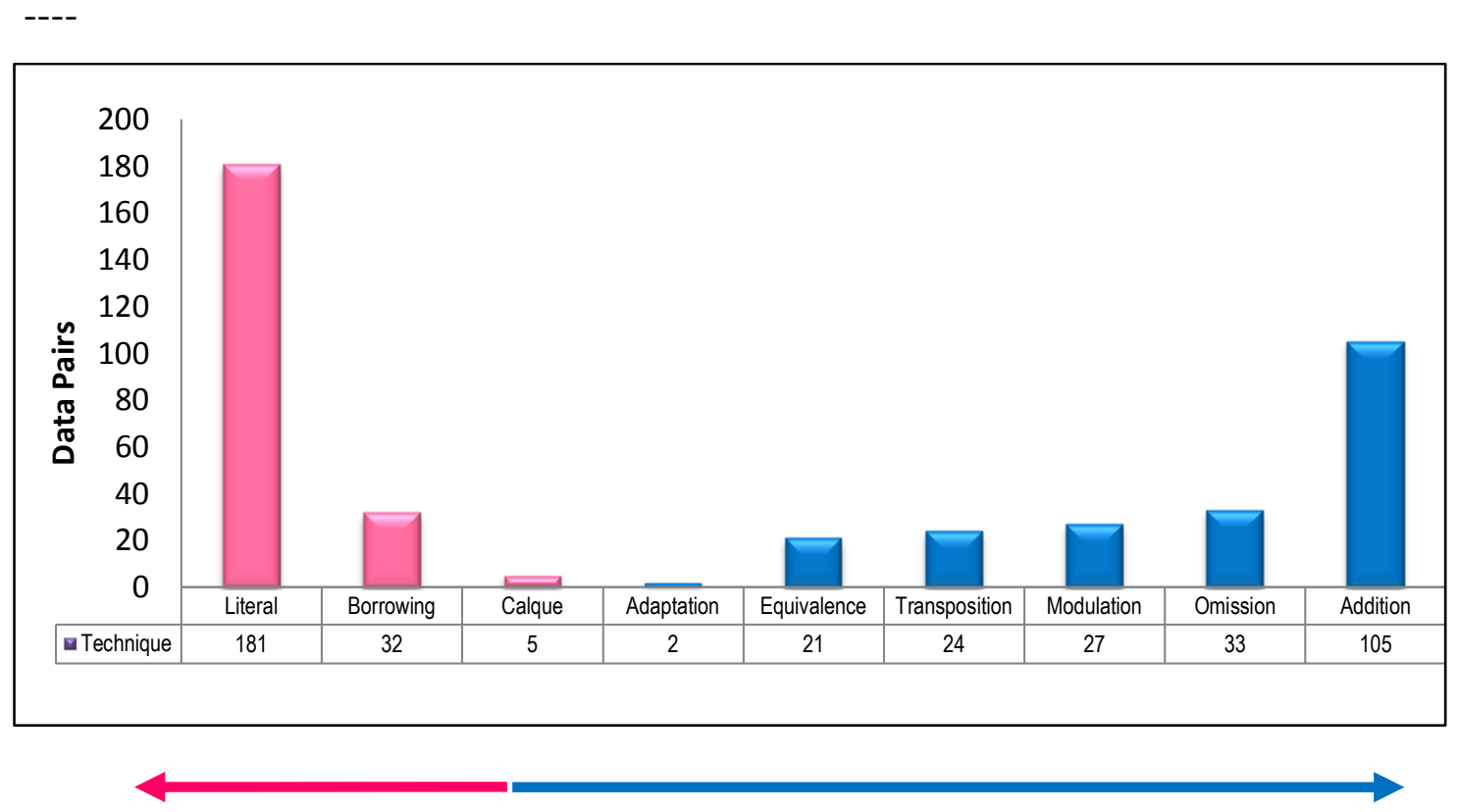

Penekanan pada Teks Sumber Penekanan pada Teks Sasaran

\section{Gambar 3.1 Prosedur Penerjemahan}

\section{KESIMPULAN}

Penerjemahan merupakan sebagai mengalihkan pesan dari bahasa sumber (BSu) ke dalam bahasa sasaran (BSa), baik dari segi makna dan gaya. Dewasa ini, terjemahan sebagai alat komunikasi semakin disadari perannya dalam perkembangan suatu bangsa terutama dalam penyebaran ilmu pengetahuan.

Bahasa yang berbeda mencerminkan nilai-nilai dan budaya yang berbeda. Oleh karena itu untuk menengahi bahasa dannilai-nilai atau budaya yang berbeda diperlukan upaya untuk mengalamiahkan bahasa sesuai dengan apa yang berterima bagi pembaca sasaran.

Dalam kegiatan penerjemahan, tugas utama penerjemah adalah mengkomunikasikan keseluruhan makna dari dua bahasa yang berbeda. Untuk itu penerjemah akan mulai dengan mengkodekan unit-unit dan struktur yang ada, yaitu dari bahasa sumber ke bahasa sasaran.
Hasil analisisterhadap korpus yang terdiri dari 430 pasangan data teks sumber dan teks sasaran menunjukkan kecondongan proses pembentukan kesepadanan teks ke bahasa sumber $50,70 \%$, sedangkan kecondongan ke bahasa sasaran 49,30\%. Terlihat bahwa teknik penerjemahan harfiah (literal) lebih dominan dipergunakan.

\section{DAFTAR PUSTAKA}

Baker, M. Ed.. (2000). Encyclopedia of translation studies. London: Routledge.

Brata, W. S. and Zein, I. (2002). The $8^{\text {th }}$ Habit: Melampaui Efektivitas, Menggapai Keagungan. Jakarta: Gramedia Pustaka Utama.

Catford, J. C. (1965). A Linguistic Theory of Translation, London: Oxford University Press.

Covey, S. R. (2004). The The $8^{\text {th }}$ Habit: From Effectiveness to 
Greatness. New York: Free Press.

Hatim, B. (2001). Teaching and Researching Translation, Harlow: Pearson Education.

Larson, Mildred,1998., Meaning-Based Translation: A Guide to CrossLanguage

Equivalence, University Press of America.

Lauscher, Susanne. 2000. Translation Quality Assessment: Where Can Theory and Practice Meet?. The Translator: Volume 6, Number 2, 2000: Special Issue. Evaluation and Translation: $149-168$

Lefevere, A. 1992. Translation, Rewriting and the Manipulation of Literary Fame, London: Routledge

Nida, E. A. 1964. Toward a Science of Translating, with Special Reference to Principles and Procedures Involved in Bible Translating, Leiden: Brill.

Siregar R. (2016) Pentingnya Pengetahuan Ideologi PenerjemahanBagi

Penerjemah.Jurnal Penelitian Pendidikan Bahasa dan Sastra Vo.1 No.1

Vinay, J.P. \& J. Darbelnet. (1989). "Translation Procedures." Readings in Translation Theory. Ed. A. Chesterman. Loimaa: Finn Lectura, 61-69.

Abrams, Dennis. "Is Indonesia a "Land Without Readers?"." Publishing Perspective. Retrieved July 27, 2015. http://publishingperspectives.c om/ 2015/06/is-indonesia-aland-without-readers/. 